\title{
Investigating self-regulation in the context of a blended learning computing course
}

\author{
Daniel F.O. Onah \\ Department of Information Studies, University College London, London, UK \\ Elaine L. L. Pang \\ Educational Development, Lancaster University, Lancaster, UK \\ Jane E. Sinclair \\ Department of Computer Science, University of Warwick, Coventry, UK
}

\begin{abstract}
Massive open online courses (MOOCs) provide an innovative educational technology, which has become widely used for distance learning by independent learners. However, there has been little work so far to study the effects of using MOOCs as part of a blended classroom approach in which learning activities take place both online and in a traditional classroom setting. This study was conducted to investigate aspects of blended MOOC usage in the context of a computing course for first year undergraduates at a UK university. The MOOC was implemented on a purpose-built platform that supports learners to make informed choices about their learning path. This research investigates students' capacity for self-regulated learning (SRL) and to understand their preparedness for independent study, profile the general areas of SRL strength and weakness, which may affect their ability to learn effectively in a self-directed environment. An existing survey instrument, based on a six-dimensional conceptualization of SRL was adapted to investigate self-regulation in MOOC study. The results demonstrate that the dimensions of self-evaluation and time management represent particular areas of weakness for these students. Further, profiles of SRL for individual students show considerable differences in capability within the study. However, the deficiencies in SRL dimensions contrast with the students' generally high levels of attainment. This leads us to question the validity of the existing SRL. Further, a high level of social interaction and help seeking was reported in relation to MOOC study indicating the increasing importance of social learning and the importance of co-regulation for SRL.
\end{abstract}

Keywords: Self-regulated learning, blended classroom learning, motivation, MOOC, e-learning development and adaptivity (eLDa)

\section{Introduction}

Technology has become a keystone for teaching and learning in the $21^{\text {st }}$ century, with the use of educational technology evolving at a rapid pace. Massive open online courses (MOOCs) have become a high-profile part of this trend, with many hundreds of courses now provided by a large number of institutions and platforms worldwide. The rush to implement MOOCs has been noted for the lack of corresponding research which is needed in order to understand areas crucial for learning such as effective pedagogy, self-regulated learning and the learner experience (Milligan et al., 2016). Such studies are now beginning to emerge, but there is still relatively little understanding of how MOOCs may be used to best effect in different contexts. In particular, 
there is a lack of published work on the incorporation of a MOOC approach as part of blended classroom teaching that will allow students to self-regulate their studies. In a blended learning approach, students study both online and in a more traditional classroom setting (Rovai and Jordan, 2004), this model aims to maximize the face-to-face classroom instruction which allows formative feedback to students on their learning (Bergmann \& Sams, 2012; Herreid \& Schilller, 2013; Sun et al., 2018). Given the large number of MOOC courses now available, and the high quality of the resources found within many, they may be able to provide a rich source of complementary material to be used in conjunction with face to face teaching in blended context. However, the two approaches of blended learning in a MOOC context represent very different styles of learning. Very little research has been conducted with regards to self-regulated learning in a blended computing course MOOC combination. For the combination to be effective, students must be effective learners in both approaches and must be able to bridge any gaps or differences between studying in different modes. Several students lack the awareness, motivation or knowledge to self-regulate their studies (Schunk et al., 2012). The six dimensions in this study illustrates results on how the proposed platform was able to investigate some aspects of students' study behaviours and SRL knowledge. The blended MOOC model offers opportunities to students to take control of their learning pace by being responsible for the learning decisions and progression (Fulton, 2012).

The current study investigates the concept of students' self-regulated learning (SRL) in the context of a computing MOOC used as part of a blended learning course presented to first year undergraduates at a top UK university (Onah et al., 2016). The study explores students' capacity for self-regulation and the levels of skill they report relating to different dimensions of SRL. This paper describes a novel MOOC platform (known as eLDa) which was developed to support students in making informed choices about their learning paths. In order to investigate these dimensions, a computing MOOC implemented on the platform was then used as part of a blended learning course, providing the vehicle through which data was collected relating to both SRL and students' experience within the blended course. In this study, we investigate the level of SRL skills of the students in the blended learning class, considering the profiles that were identified among the students using the six measuring dimensions. The results within this study showed that students' use of help seeking strategies had positive impact on their ability to seek for in-class support and lastly, provide within the result sections, observation of the area of weakness that required improvement in the pedagogy.

\section{Related review}

\section{Blended learning}

The "blended classroom" is an approach to teaching and learning which incorporates online learning resources into a course partly delivered using a more conventional class setting (Rovai and Jordan , 2004). Students studying in a blended mode engage with online course content anywhere and at any time they choose, in addition to participating in face-to-face sessions in a "bricks and mortar" classroom at their institution (Graham, 2006). Blended learning is seen as a way to harness the many rich resources available on the Internet, while retaining the benefits of more traditional instruction available in on-campus courses (Cunningham and Billingsley, 2002). Advantages are said to include a reduction in cost, an additional flexibility in study, and the availability to students of different perspectives, presentations and examples relating to the same topic to learners of diverse backgrounds (Barnard et al., 2009; Sharma and Barrett, 2011). Blended learning has also been associated with an increase in learners' autonomy, with students taking control of their studies and of the study environment outside the timetabled instructional classes (Cunningham and 
Billingsley, 2002). It is further suggested that, as well as reducing the limitations of time, environment and resources, blended learning can engender within the learners an enthusiasm to continue their work outside the classroom and to study consistently (Cunningham and Billingsley, 2002). This may partly explain results linking blended learning to improved retention rates and improved attainment (Lopez-Pérez, 2011).

In order to conceptualise and understand pedagogic issues relating to blended learning, theories and principles of education which have been applied variously to online learning environment or to a traditional learning setting need to be modified (Broad, 1999). Research findings relating to one particular mode of delivery may not always transfer to a different way of teaching and learning. Hence, in order to develop appropriate approaches to teaching and learning in a blended context, research is needed either to confirm findings previously established or to develop specific, new evidence-based theory and practice. A variety of different models have been proposed for the blended learning paradigm with, for example, varying ways of managing the balance between classroom and online instruction (Graham, 2006). This underlines further the need for understanding of concepts and theories in the different contexts encountered.

The advent of MOOCs has provided a new class of freely-available learning resources which can potentially be used as part of a blended learning experience. A limited amount of work is now emerging relating to this. Initial results indicate that students respond well to the approach and that there is the potential for increasing student autonomy by the use of this approach (Bruff, 2013; Orsini-Jones, 2015). However, there is still much to be learned about the interpretation of existing theory in the different contexts and of the students' experience of study in a blended MOOC classroom.

\section{Self-regulated learning}

Self-regulated learning (SRL) refers to learning which is directed by a meta-cognitive reflection on one's own learning process and by the conscious choice of appropriate strategies to maximise learning (Zimmerman, 2000; Zimmerman, 1998; Bandura, 1991). Self-regulated learners do not simply seek to take in information presented to them, but are proactive in taking control of their learning (Zimmerman, 1998). Self-regulation is itself affected by motivational factors such as the learners' commitment to current learning goals and their belief in their own capability to succeed in the learning endeavour (that is, their self-efficacy) (Zimmerman, 2008; Bandura, 1997). Self-regulation is generally characterised as comprising a number of distinct dimensions which play a central role in learners' motivation, engagement and learning behaviour (Dweck and Grant, 2008; Boekaerts and Corno, 2005; Bandura, 1991; Zimmerman, 2008). SRL is strongly associated with a range of positive outcomes such as high attainment and lower drop-out rates (Zimmerman, 2000; Kramarski and Mizrachi, 2006; Lan, 1996; Chang, 2007). It is therefore highly desirable to understand students' levels of SRL and to help students recognise and improve areas of weakness.

A number of conceptualisations for SRL exist and, based on these, several survey instruments have been developed to investigate students' capacity for SRL and to expose areas of weakness which need to be addressed (Zimmerman, 2000). These have been deployed in both a traditional setting and an e-learning context. For example, in studying SRL of learners within two MOOCs, Milligan et al found that those with high SRL levels were more likely to set specific learning goals (Milligan et al., 2016). However, the concept of SRL and the activities that evidence it may differ according to the various learning contexts. The most effective strategies for scaffolding and supporting SRL may differ between types of student and modality of learning (Ting and Chao, 2013; Winters and Azevedo, 2005). Further, the role played by SRL in distinct educational settings may be different. For example, investigating the way in which the self-efficacy aspect of SRL relates to other elements within a community of inquiry, Shea and Bidjerano found differences between the effects noted in a blended learning environment and those observed in a fully online course (Shea and Bidjerano, 2010). While the implications of such results need further investigation, the work clearly points to 
differences both in what constitutes effective self-regulation and in the difference that such skills make within various different learning environments.

Another connection made in some studies is that between learner autonomy and self-regulation (Zimmerman, 1998). A mode of working which allows students the freedom to make decisions about what and how they study can encourage them to take control of their own studies, helping them to engage better and achieve better academic performance (McManus, 2000; Bowen, 1996). In this respect, it might be thought that blended learning has distinct advantages in that students experience autonomy in part of their study but also have some direction by teachers to guide them on how to learn. This may be a promising scenario for developing SRL skills in a supported way, however, it may also potentially cause some confusion if the skills required differ between environments. Differences have been noted between higher- and lower-achievers levels of action control (an aspect of SRL relating to the ability to ring-fence time on task despite competing demands) (Ting and Chao, 2013). However, it is unclear whether this applies equally to the different blended modes or if it is significantly different to single-mode learning. Other areas of difference may also be relevant in a blended learning context. For example, students' different motivational beliefs have been shown to have an influence in promoting and sustaining their SRL (Pintrich, 1999). Hence, differences in motivational approach to learning modes could potentially lead to material differences in a learner's SRL between those modes.

Although there have been suggestions that some "traditional" dimensions of SRL conceptualisation may have less (or more) significance in a blended learning context, it is not yet understood which aspects this applies to or to what extent the differences occur. For example, Lynch and Dembo found that neither the help-seeking dimension of SRL nor a capacity for Internet self-efficacy were predictive of success in a blended learning environment (Lynch and Dembo, 2004). In this case, there is no indication as to whether levels of help-seeking and self-efficacy were really lower, or whether the questions asked were not correctly targeted to elicit information appropriate to the modality of learning. This points to the need for further research which explores the issue of self-regulation in the context of blended learning in order to understand what constitutes SRL in different modalities and how it can be fostered. Existing research clearly demonstrates the benefits of analysing learning data and applying the results to inform better course delivery (Fournier et al., 2011). To better understand how learning technology can enhance the learning process it is necessary to investigate both the learning environment and the experiences of the learners themselves in relation to the environment. This study investigates dimension of SRL exhibited within a blended learning computing class. The blended element is provided by a MOOC which is itself implemented on a novel platform that supports users' choice of learning path hence increasing the opportunities for learner autonomy. The following section discuss the research questions and theoretical framework underpinning the study and the data collection process.

\section{Theoretical and research framework}

The principle aim of this study is to investigate levels and patterns of self-regulation demonstrated by "traditional" undergraduate students on a module conducted using a blended learning approach. The students were all studying on a conventional, face-to-face computing degree programme. The main mode of learning that most of the group had experienced up to this point was that of conventional classroom teaching. For the online component of the blended course, a MOOC was provided. This reinforced and developed the ideas introduced in classes and allowed students to engage with the course and to interact with their peers and their tutor outside the class seminar times. The authors built upon this study from an earlier investigation on a the first cohorts conducted in 2016 for students engaging in a computer security module from a top UK university (Onah et al., 2016). In the study, the authors investigated the ability of these cohorts of students to self-direct their studies toward attaining better academic grades (Onah et al., 2017). Data relating to SRL was collected from the students using a modified version of an existing SRL survey instrument (Onah et al., 2015) as 
described in the section "Data collection process". The study was conducted with a class of students enrolled for an existing module and was conducted as action research. That is, an innovation was introduced to existing practice, with data collected to allow evaluation of the change and reflection on its implications for future practice.

The study investigates dimensions of self-regulation using a survey approach to gather students' self-reported SRL data. An existing survey instrument appropriate to investigating SRL in an online context was selected (Lan et al., 2004). This instrument is known as the online self-regulated learning questionnaire (OSLQ). It is based on a conceptualisation of SRL which covers six separate dimensions: (i) goal setting, (ii) task strategies, (iii) time management, (iv) environment structuring, (v) help seeking and (vi) self-evaluation. OSLQ has been validated and used in a number of previous research studies (Lan et al., 2004; Barnard et al., 2008).

The current study considers the same six dimensions. However, in order to represent the context of a MOOC more appropriately, some of the questions have been adapted and several have been added. Indicative examples of the questions evidencing each dimension are given in the results section below. We refer to the adapted version of the survey used in this study as MOSLQ.

\section{Research questions}

The main research questions explored in this work were:

1. How accurate is the existing survey instrument of the six-dimensional conceptualization of SRL previously used in an online study relevant in a blended learning course?

2. What are the various level of SRL skills observed among the learners' profile within the blended-learning computing course?

3. What areas of weakness in self-regulation are observed which can help inform future improvements to the course pedagogy and co-regulation for SRL?

\section{Data collection process}

The study evaluated students' perspectives and SRL profiles within a blended seminar classroom trialled with first year undergraduates studying a computing security course at the University of Warwick, United Kingdom. Two questionnaires were used to elicit data. The first was a general survey administered in order to understand the students' demographic and their previous experience of blended learning. This consisted of 37 questions and was administered early in the course to help shape the approach to teaching and to determine appropriate scaffolding to accustom students to the blended approach. The 37 questions comprised a combination of Likert scale responses (with strongly agree as the highest level and strongly disagree as the lowest level) and free-response questions to gather students' thoughts and impressions of the MOOC-based blended approach.

As described above, the MOSLQ survey instrument was used to investigate SRL and this formed the basis of the second survey. Each of the separate SRL dimensions was evidenced by four or more questions eliciting the extent to which the student engaged in a specific activity related to that dimension. Responses are on a 5point Likert scale.

The online component of the blended classroom seminar was provided by a MOOC hosted on a novel MOOC platform known as eLDa (described in the section "Results"). Several additional questions were incorporated into the second survey instrument to discover students' views on the appropriateness of the MOOC content, 
the supportiveness of the delivery method and the general utility of the platforms. In total, the second survey comprised 31 questions.

The course had 136 registered students in total. The trial group consisted of 27 students who formed one seminar group. The first questionnaire was administered to all 27 students within the group. Voluntary participation was later sought for the SRL survey, with a paper copy of the instrument distributed in a faceto-face seminar session. There were 17 responses received for this second survey in the blended classroom learning. The data collected from both surveys was subjected to both descriptive and predictive analysis using the SPSS (Statistical Package for the Social Sciences) statistical tool. The survey tool was not exactly the same for the both data collection as the instruments were administered differently; the first consist of an initial demographic and understanding of their previous learning habits, and the second was based primarily on the six SRL dimensions, with some questions specific to the students' learning approach.

\section{ELDA platform}

ELDA is a novel MOOC platform developed and opened freely for participation. This platform gives learners the option to decide their path of study (Figure 1). The blended and online learning courses developed are structured in a more traditional MOOC manner, with the learner following a predetermined instructional approach suggested to accomplish the full learning objectives and set goals of the course. Alternatively, the platform provides the necessary support for learners to pick parts of the course without following a linear trajectory through staged sessions. The infrastructure needed to do this includes a mapping of prerequisites for different topics, means for the user to determine their preparedness to attempt a particular topic, and progress visualisation for users to see which parts of the course they have completed. The learner is thus supported in self-direction of their study and can, if they choose, achieve greater autonomy in their learning.

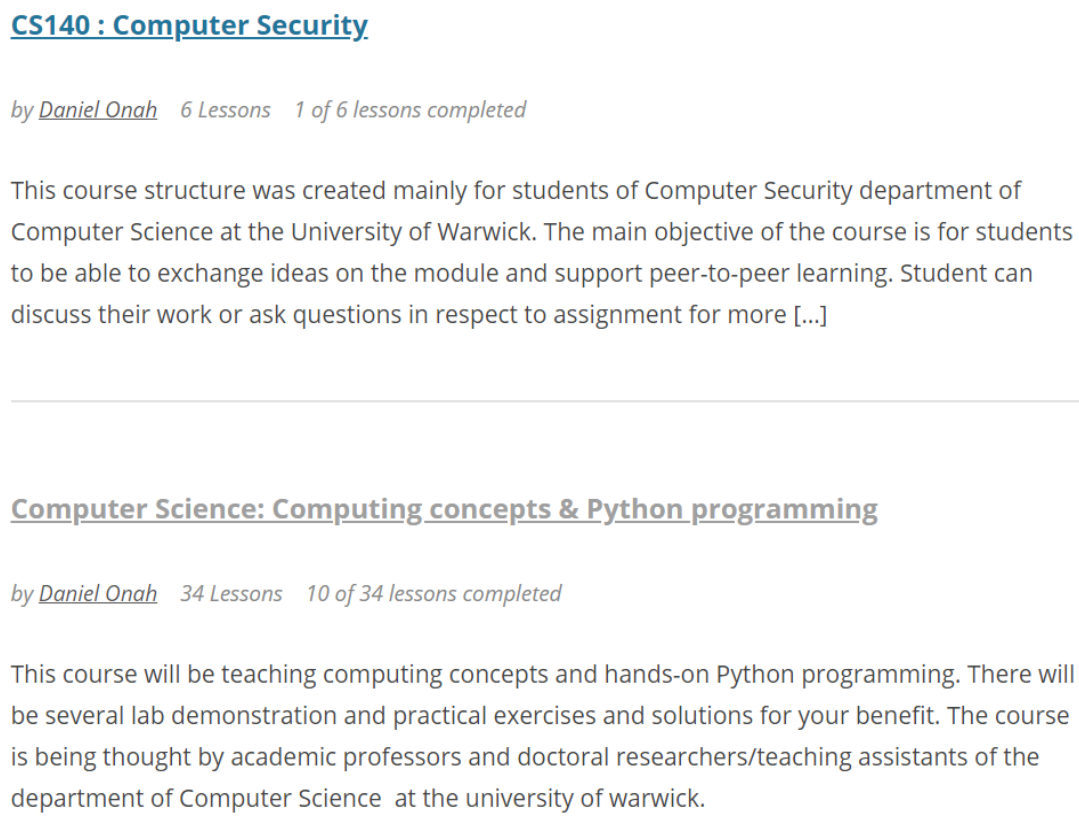

Figure 1. eLDaMOOC platform showing blended learning and online courses 


\section{Purpose of the course platform design}

Modern educational learning tools should be constructed to meet the required needs and expectations of the learners, thus this could foster motivation and commitment (Onah et al., 2015; Mayes and De Freitas, 2007). It is arguable that modern technology could only play a significant role of achieving learning design outcomes. The modern pedagogy design is an enhancement of existing learning design approaches. With the additional functionality and the features or components determine by the learning platform, this could also direct the learners in making an informed choice of route during the learning process. Moreover, the basic principle is to describe how the various processes are common within all the learning modes underlying in the technology to function effectively in order to enhance learning experience (Mayes and De Freitas, 2007; Beetham and Sharpe, 2007; Beetham and Sharpe, 2013). According to Taylor et al., in their study argued that radical change depends on making explicit and improving the collective learning of individual across all sectors. This platform provides an opportunity for learners to decide their route to study either in a self-directed mode or in an instructor-led mode. These different modes could not be made possible without the incorporation of novel features and components to support the process in the learning platform. To support this for the MOOC to be presented as part of the blended approach, a novel platform (known as eLDa) was developed for which undergraduate computer security module was embedded in. This provided functionality to support learners' self-direction by means of features enabling informed choice of prerequisites for different topics and visualisation of topics studied so far. Additional features, such as private messaging, allowed greater social interaction. Thus, in addition to supporting engagement with course topics and resources outside the face-toface classroom sessions, the MOOC also gives students the opportunity not just to engage with course topics and resources at times of their own choosing but also to interact with each other and discuss course issues outside conventional class times.

Provision of a blended MOOC enhances students' opportunities for learning and provides supplementary material. Existing best practice concerning digital and blended learning was sought in the literature and was employed in the development of the course (Mayes and De Freitas, 2007; Beetham and Sharpe, 2007; Beetham and Sharpe, 2013; Tallent-Runnels et al., 2006; Biggs, 2011). In particular, the authors were careful to adhere to good pedagogical design practice that no inconsistencies develop in the curriculum, the teaching approaches, the learning environments and the assessment procedures. The learning outcomes were carefully defined, with learning and teaching activities selected to meet these outcomes. A range of different materials was provided in order to support students with different learning preferences and approaches. Similarly, assessment tasks (both assessed and those provided for self-evaluation) were designed to test the students understanding contributing towards the intended learning outcomes (Figure 2). 


\title{
My Courses
}

\author{
My Messages \\ Active Courses \\ Completed Courses
Computer Science: Computing concepts \& Python programming
by Daniel Onah 34 Lessons

Figure 2. Visualisation of course completed

\section{Blended course architecture}

The overall blended learning architecture is demonstrated in Figure 3. The students were registered into the eLDa platform by the instructor and login details sent to each student via e-mail. The students are presented with a visual map of the lesson for that week and previous weeks for revision. The lessons content are delivered every week. Each lesson had class exercises and solutions which were embedded in the module. Part of the class exercise was done during the blended session and the students' in-turn can go through the online solutions after the seminar class. Thus, this is another element which promotes learner reflection and self-evaluation of their understanding of the seminar lesson. In addition, this enables students to understand better and encourage studying further.

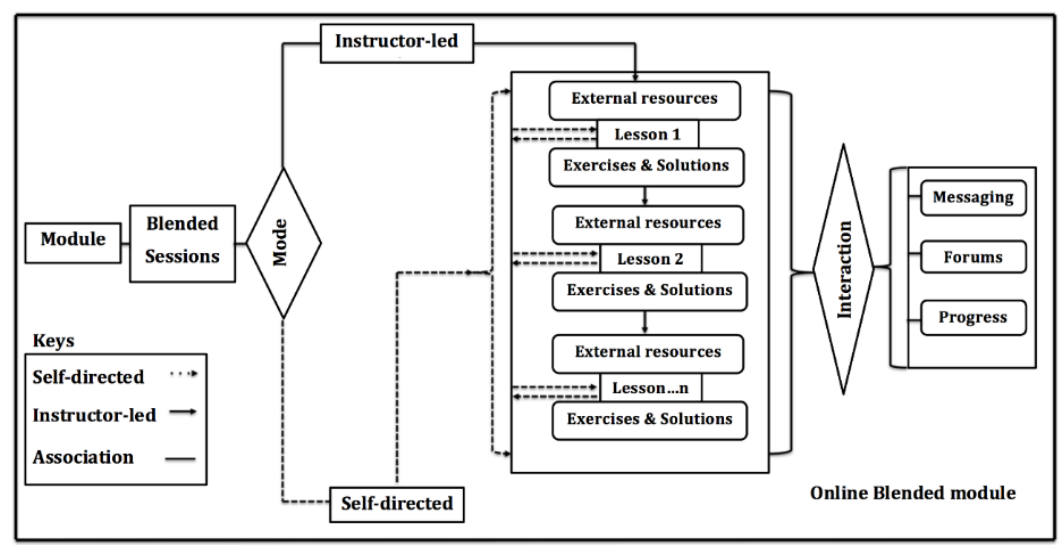

Figure 3. Architecture of the online blended module 
Our observation shows that most of the students who constantly engaged and participated in the community forum found it beneficial. The tutor also used this forum to communicate with the students and provide support with external resources suitable to aid the conventional assessment as seen in Figure 4.

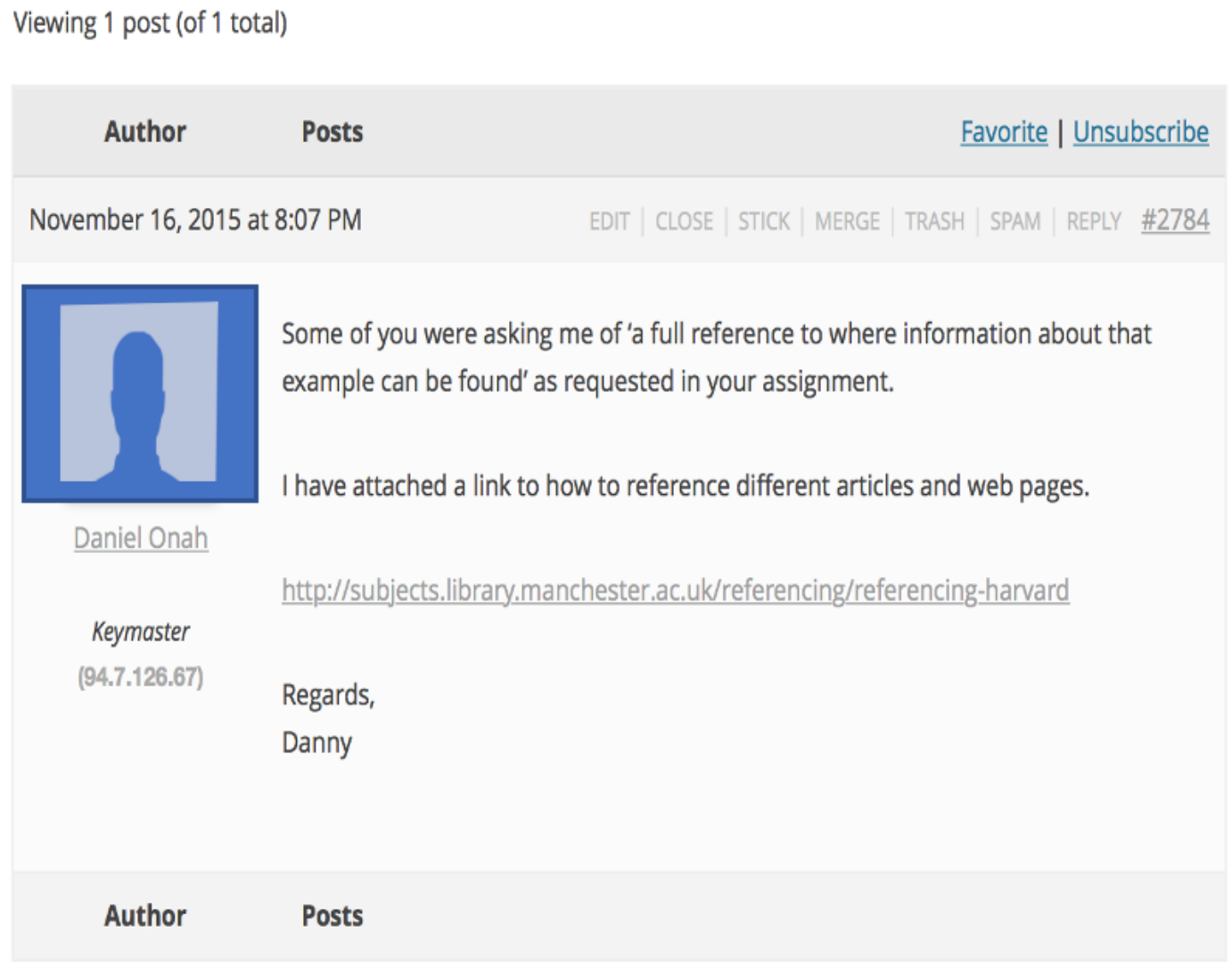

Figure 4. Visualisation of course forum

Progress map: In order to support the students to follow the lessons in an orderly manner and to enlighten them of those not yet studied, a visualisation of the lesson component was incorporated into the blended module. This visualization provides the students with individual view of lessons completed and those yet to be studied. Figure 5 illustrates a progress map of a session in the eLDa platform course. This stands as a support to re-route and direct the students to the next lessons promptly without any time waste. 


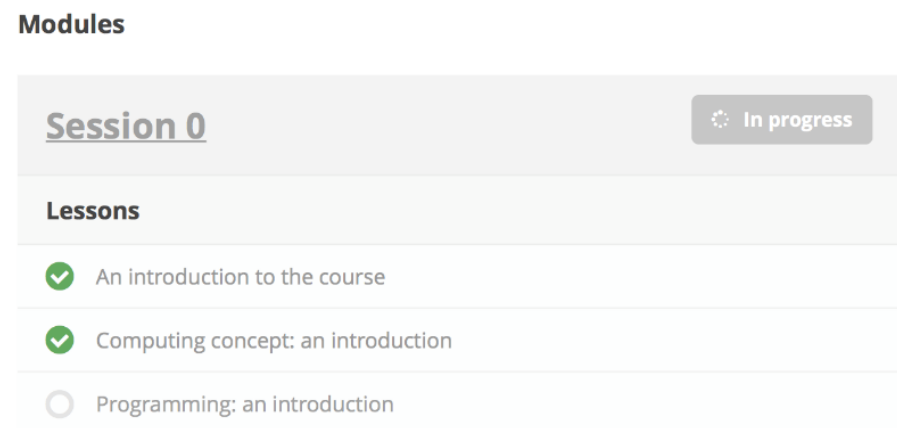

Figure 5. Visualisation of lessons completed and those yet to be studied

\section{Results}

Data collected from the study were analysed using SPSS. Here, we report descriptive statistics from the evaluation, using these to suggest significant features of students' SRL and the patterns observed to occur in the blended learning environment. This section reports results from the first survey with 27 respondent and onwards present results related to the 17 responses to the second survey.

\section{The research participants}

When students were asked if they had participated in a blended class before this study, over $85 \%(\mathrm{n}=23$ students) said they had not. Only $14 \%(n=4$ students) said they had (Figure 6). Thus, most students were unfamiliar with this type of learning. The proportion of male to female students in percentage indicates approximately $93 \%(n=25)$ male and $7 \%(n=2)$ female.

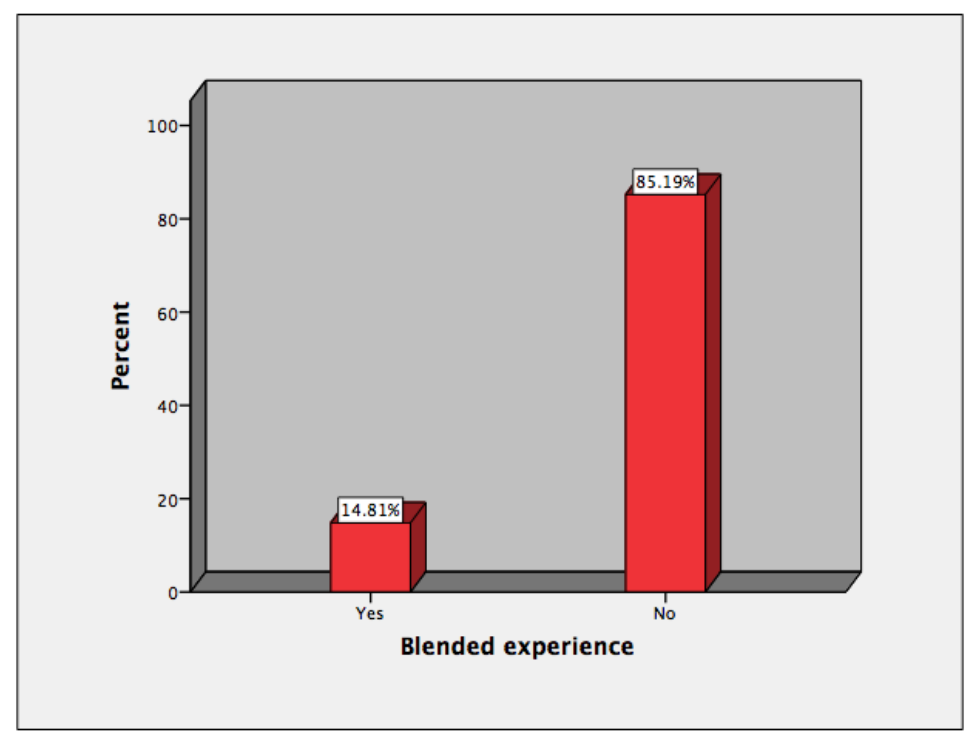

Figure 6. Percentage of students who have and have not previously participated in a blended class. 


\section{SRL Dimensions: survey responses}

This section presents two selected statements from each of the SRL dimensions and the responses received. These selected responses enable the provision of the important aspect of learning identified in the study which is prominent within the blended-learning students. The reason for choosing two statements for each dimension was to provide the vital aspect of the key views that are relevant to this investigation and of which this study is interested in exploring among these students (see Table 1).

Table 1. Showing response to the survey

\begin{tabular}{|c|c|c|c|c|c|}
\hline \multirow{2}{*}{$\begin{array}{c}\text { SRL } \\
\text { Dimensions }\end{array}$} & \multicolumn{5}{|c|}{ Likert Scale \% } \\
\cline { 2 - 6 } & $S A$ & $A$ & $N$ & $D$ & $S D$ \\
\hline GS1 & 5.88 & 52.94 & 11.76 & 23.53 & 5.88 \\
\hline GS2 & 17.65 & 52.94 & 19.41 & - & - \\
\hline TS1 & 11.76 & 52.94 & 23.53 & 5.88 & - \\
\hline TS2 & - & 5.88 & 58.82 & 29.41 & 5.88 \\
\hline TM1 & 11.76 & 23.53 & 41.18 & 23.53 & - \\
\hline TM2 & - & 25.00 & 37.50 & 18.75 & 18.75 \\
\hline ES1 & 17.65 & 58.82 & 17.65 & 5.88 & - \\
\hline ES2 & 5.88 & 41.18 & 23.53 & 29.41 & - \\
\hline HS1 & 23.53 & 35.29 & 17.65 & 17.65 & 5.88 \\
\hline HS2 & 23.53 & 29.41 & 11.76 & 29.41 & 5.88 \\
\hline SE1 & - & 29.41 & 47.06 & 17.65 & 5.88 \\
\hline SE2 & - & 41.18 & 29.41 & 17.65 & 11.76 \\
\hline
\end{tabular}

\begin{tabular}{l|l|l|l|l|l} 
GS - Goal setting & TS-Task strategy & $\begin{array}{l}\text { TM-Time } \\
\text { management }\end{array}$ & $\begin{array}{l}\text { ES - Environment } \\
\text { structuring }\end{array}$ & HS - Help seeking & $\begin{array}{l}\text { SE - Self } \\
\text { evaluation }\end{array}$
\end{tabular}

Goal Setting: The goal setting question present a response when students were asked to respond to the statement 'I set goals to help me manage studying time for my blended classroom lecture seminar'. The result indicates $52.94 \%$ agreed to the statement as seen in GS1. GS2 is in response to the statement 'I set standards for my weekly assignment after the blended class', this shows over $70 \%$ of the students said they set standards to achieve success in their weekly assessment. This statement is reflected in their final assessment results as shown in Table 4.

Task strategies: In the task strategies dimension, response to the statement 'I find the solutions to problems in the blended class or any online courses aided me to master the content', reveals that $58.82 \%$ of the students agreed to the statement and $11.76 \%$ of students strongly agreed. This indicates that majority of the blendedlearning students find the solutions to problems during the course very useful to aid their studying patterns as seen in TS1. TS2 shows the response to the statement 'I prepare my questions before contributing in this blended class or any online discussion'. The results show over $58 \%$ of students neither agreed nor disagreed to this statement, over $29 \%$ of the students disagreed and only about over $5 \%$ agreed. This statement confirmed that the students in this study are new to this method of learning as stated earlier. 
Time management: When students were asked about their time management skills in this statement, ' $I$ allocate some time to my online blended classroom seminar to acquire more knowledge', only 35.29\% agreed or strongly agreed (as shown in Table 1, TM1). This is a similar profile to responses for other questions in the time management dimension. TM2 is in response to the statement 'I try to schedule some time every week to prepare for my online blended classroom seminar'. This reveals about $25 \%$ of the students agreed that they set aside preparation time before engaging with the weekly seminar component of the blended-learning course. Slightly over $37 \%$ disagreed.

Environment Structuring: The students in the study show evidence of their individuality and preference of study environment when they were asked to respond to the statement, 'I choose my preferable environment to study in order to avoid any distraction', majority of the students were positive in their responses. Most of the students about $58.82 \%$ agreed to the statement and while $17.65 \%$ strongly agreed as illustrated in ES1. When the students in this study were asked to respond to the statement 'I choose a certain period with less noise for my blended learning', most of the respondents of about $47 \%$ agreed that they select better times and a quiet environment to study. This is to enable them to be surrounded with a nice atmosphere with less noise so that they could have better understanding of their studies as shown in ES2.

Help seeking: Regarding the help seeking statement 'I find a colleague who is knowledgeable in the course content so I can ask him or her when I need any help', 35.29\% agreed to the statement and $23.53 \%$ strongly agreed as seen in HS1. This result indicates students' willingness to ask for help both from their peers and from tutors. HS2 shows the students' response to the statement 'sometimes I meet my classmate one-on-one to discuss exercises and assignments'. This indicates that majority of the students over $52 \%$ like engaging in a group learning with friends sometimes.

Self-evaluation: In terms of self-reflection or self-evaluation while studying, the students' responses to the statement, 'I summarize my blended classroom learning to examine my understanding of what I have learnt', shows $29.41 \%$ agreed as reveals in SE1. This reveals that very little students are willing to give accurate response to the question or may be due to the fact they are new to this blended learning approach, they could not understand fully the importance of self-evaluation while studying. The study shows that the students on their own discussed with their mates to reflect if what they have studied and understood in the blended class is what others understood as well. SE2 reveals this in response to the statement 'I discuss with my classmates to see whether what I understood during the blended classroom is what they understand as well', about over $40 \%$ agreed to the statement.

\section{Measuring Overall Self-Regulated Learning Skills}

The previous section selected indicative questions from each of the SRL dimensions showing responses in detail to these specific questions. Overall, the six dimensions were evidenced by the following numbers of questions: goal setting (GS), 5; environment structuring (ES), 4; task strategies (TS), 6; time management (TM), 4; help seeking (HS), 4 and self-evaluation (SE), 4. These questions all had a 5-point Likert response format, with values ranging from strongly agree to strongly disagree. To calculate an overall score for each dimension, a numerical value was attached to each response level from 5 for strongly agree to 1 for strongly disagree. Figure 7 shows the average scores for each question asked. It shows that, even within a single dimension, scores are not necessarily consistent. Hence, there are specific areas of each dimension that might be considered targets for improvement. For example, support may be needed for Task strategies TSQ1: 'I read aloud while engaging with the instructional material in this blended class to avoid distractions' and TSQ2: 'I 
prepare my questions before contributing in this blended class or any online discussion' but students are generally proficient in TSQ3: 'I find the solutions to problems in the blended class or any online courses aided me to master the content' and TSQ4: 'I try to take in more notes during the blended classroom seminar to improve my ability to study.

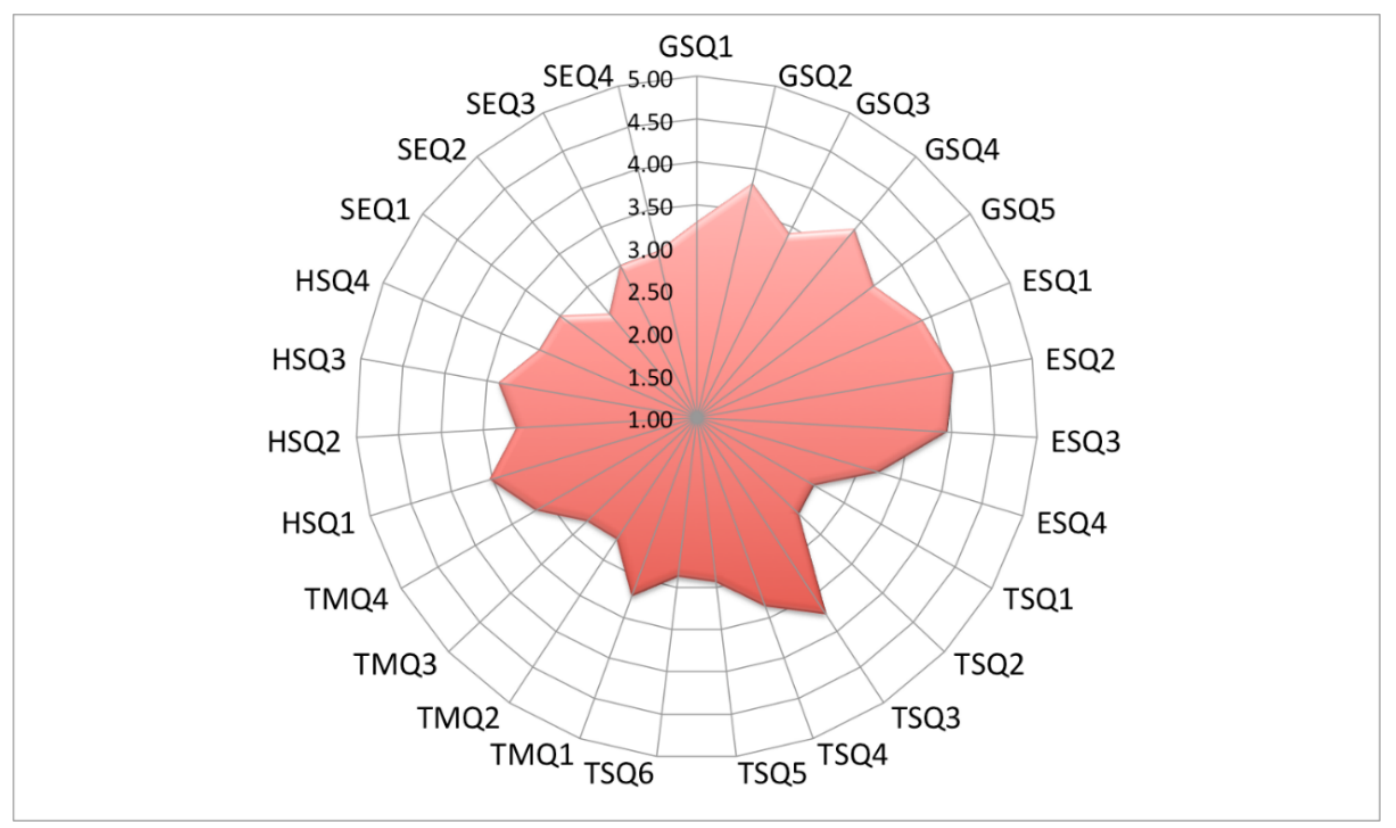

Figure 7. Visualisation of average SRL scores for the MSLQ

Table 2 shows the overall average scores of the MSLQ grouped into six dimensions, with a visualisation of this result shown in Figure 8. These clearly show that the dimensions of greatest weakness are self-evaluation and time management. On the other hand, students demonstrate that they understand the need to set goals and to structure their environment and they are focus on carrying out activities related to these dimensions. This result reveals the overall mean dimension as 2.63 which when rounded to the nearest integer is exactly the 3.0 threshold set as acceptable score level for high SRL achievers.

Table 2. Overall average score for each of the six dimensions

\begin{tabular}{c|c|c|c|c|c}
\hline GS & TS & TM & ES & HS & SE \\
\hline 3.60 & 3.03 & 2.97 & 3.78 & 3.25 & 2.90 \\
\hline
\end{tabular}

Mean: 2.63 


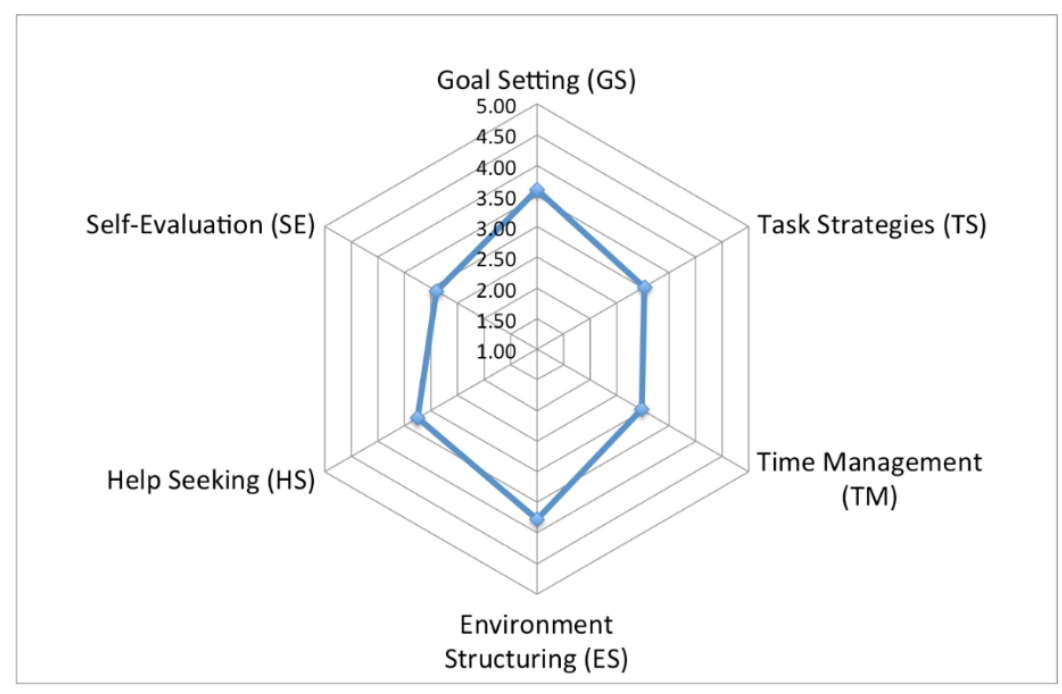

Figure 8. Visualisation of overall average SRL dimensions

\section{Results by individual students in a blended learning}

Table 3 illustrates the average SRL scores for individual students. There is considerable variation between scores observed for different students ranging from a high score of 4.14 to the lowest score of 2.43. The majority of students have an average falling between 3 and 4 . 
Table 3. Average score for each student.

\begin{tabular}{l|c}
\hline \hline Learners & $\begin{array}{c}\text { Average SRL } \\
\text { Score }\end{array}$ \\
\hline Learner 1 & 3.54 \\
\hline Learner 2 & 2.80 \\
\hline Learner 3 & 3.76 \\
\hline Learner 4 & 2.59 \\
\hline Learner 5 & 3.10 \\
\hline Learner 6 & 3.40 \\
\hline Learner 7 & 3.46 \\
\hline Learner 8 & 3.88 \\
\hline Learner 9 & 3.58 \\
\hline Learner 10 & 3.23 \\
\hline Learner 11 & 4.14 \\
\hline Learner 12 & 2.43 \\
\hline Learner 13 & 3.68 \\
\hline Learner 14 & 2.57 \\
\hline Learner 15 & 3.18 \\
\hline Learner 16 & 2.94 \\
\hline Learner 17 & \\
\hline
\end{tabular}

Further to the result from Table 3, there is notable discrepancy in specific dimensions between different students as shown in Figure 9. For example, one student (Learner 12) claimed never to engage with any of the self-regulation activities relating to self-evaluation, hence scoring the minimum possible level (1) on this dimension. In contrast, Learner 17 scored 4, indicating a high level of importance placed on reflection and evaluation. The most consistently high-scoring dimension across all students was environment structuring, demonstrating that students actively consider where and how they study best and take appropriate action to ensure a suitable working environment. The result reveals overall mean of the learners' average as 3.31, which falls between the thresholds of high achievers within this cohorts of learners. 


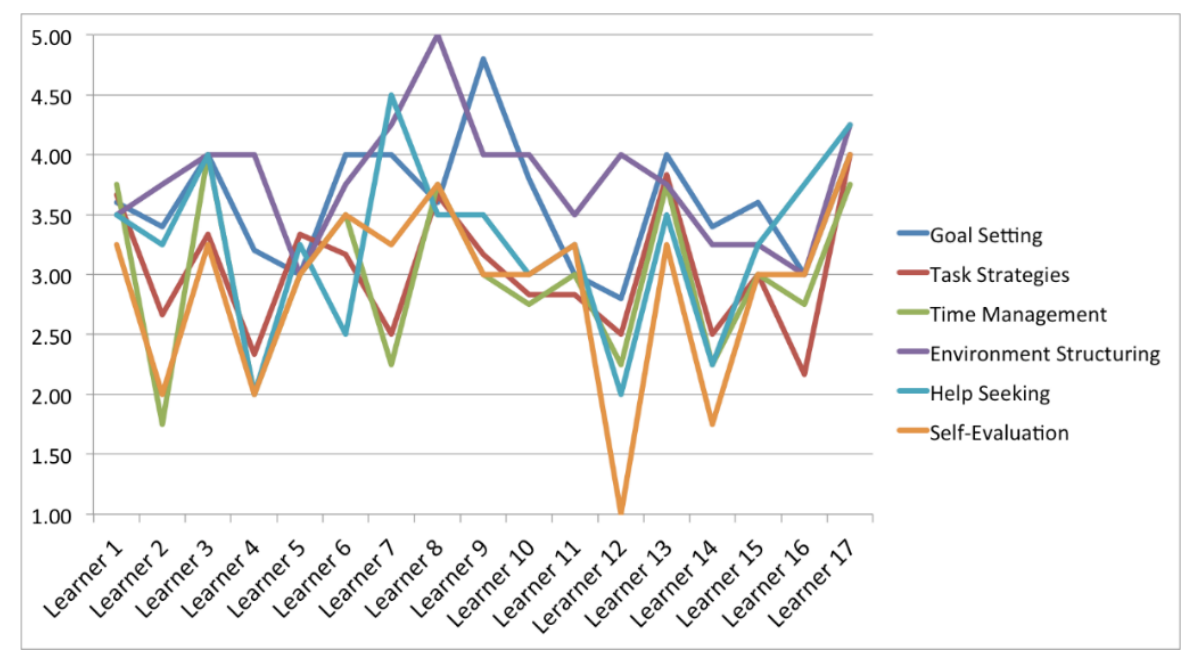

Figure 9. Individual student's SRL score with respect to the six dimensions.

\section{Average weekly assessment marks}

Table 4 shows the average mark obtained by this group of students in each of four weekly assessment tests incorporated in the module. The maximum mark obtainable was 25 in each case. The students were performing at or above the level that would be expected for this module. Even though SRL skills were low for some students in some dimensions, overall the students were obviously approaching and organising their studies in ways which worked for them and allowed them to perform reasonably well. However, it may be that with greater focus on self-regulation and support for areas they are currently neglecting, their study could be improved even further.

Table 4. Student average weekly assessment marks.

\begin{tabular}{c|c|c|c}
\hline Mark 1 & Mark 2 & Mark 3 & Mark 4 \\
\hline 21.77 & 21.18 & 24.11 & 23.02 \\
\hline
\end{tabular}

Mean mark: 22.52 (each mark is out of 25)

\section{Discussion}

The research questions in this study focused on the SRL skills demonstrated amongst students in a blended classroom, investigating patterns of self-regulation and discovering areas that might benefit from improvement. The overall average score for each of the six SRL dimensions score shows that in no dimension does the group as whole reach what we have classed as a high level of self-regulation. This might be thought to indicate that all areas would benefit from improvement for most students. From the demographic data, it was found that the majority of students had no experience of blended learning so it may be that at this stage they were still coming to understand the rationale and concepts of SRL in a blended context. It is interesting to note that all of these students are high achievers in the sense that they have obtained entry to a highly selective research-led department at one of the top universities in the UK. Hence, they would be expected to 
be effective in self-regulation of their learning. The scores obtained in their weekly assessments indicate a rise by the third week which could support the hypothesis that there is a necessary adjustment in order to study within the blended environment in the most effective, self-regulated way. As high achieving students (and with appropriate support), the class members were able to start making the necessary adjustments to their learning behaviour in the period of the study and it might be predicted that this would improve further as they became increasingly used to the mode of study. This explanation would align with the view of SRL being a context-dependent concept (Zimmerman et al., 1996).

Considering the profiles of individual learners, there is a notable variation between learners with respect to self-regulation. Several obtained average scores of over 4, indicating a very good all-round attainment on all dimensions. This contrasts sharply with the students whose average is lower than 3 , indicating that they actively disagree with most statements which would demonstrate their engagement with online SRL practices. Again, this reinforces the message that students who are effective, self-regulated learners in one mode of learning cannot automatically be expected to self-regulate in an unfamiliar mode. Support is therefore needed to help learners adjust and develop their practices of self-regulation for learning when they are confronted with a new approach to learning. In particular, first year students who are used to a very structured traditional classroom environment in their school may need support in some aspects of SRL for blended learning. Further, given the different patterns exhibited by students across questions even within a single dimension it is possible to offer appropriate scaffolding targeted to each learner's personal profile.

Looking at the skills that were generally most lacking at the point of SRL assessment, we note that selfevaluation and time management are lowest. Time management is often noted as a common problem for many students and it may be that a blended mode of learning, which allows greater autonomy of study in at least part of the course, may present additional challenges. For some students, it may be that scheduling the tasks in amongst other work and social activities is problematic. For others, distractions of working online might be an issue. Some of the results from the tables and graphs reflects promising findings that when observed from a large study could lead to significant research outcome.

There could however be a different interpretation to our findings. Although the current study has concentrated on the quantitative data collected, the free-form response questions did allow students to express some of their ideas and experiences of study. It is interesting to note that in these responses, students indicated some of the strategies which they felt helped them motivate themselves to study, schedule tasks effectively and manage their time. One student described how they would challenge themselves in playing an online game: when they lose then they start to study. Another student found that they studied best immediately after playing sports because they feel motivated and able to work more effectively. These strategies obviously differ between students and the "self" aspect of SRL underlines the importance of helping students discover what works best for them. Further, traditional conceptions of what constitutes effective study practice may no longer be universally applicable. Research investigating study habits reveals a range of (sometimes surprising) activity which appears highly effective for individual learners (Oliver, 2016). Hence, it may be necessary to ask whether questions asked in current survey instruments are the most appropriate to investigate the concept of SRL and indeed whether the conception of SRL which informs them is suitable for novel learning contexts. 


\title{
Conclusions and future work
}

There has been little research on the effects of using a MOOC as the online component of a blended classroom learning approach. This study has used a theoretical perspective of self-regulated learning to investigate approaches to self-regulation adopted by undergraduate computer science students studying in a blended MOOC environment. The MOOC used for this purpose was developed on the innovative eLDa platform, allowing students to determine, track and visualise their individual path through topics and materials offered in the MOOC.

Data collected using a standard conceptualisation of SRL for online learning revealed relatively low average levels on several dimensions: notably, self-evaluation and time management. Our findings lend support to the view that SRL is a contextualised concept and that, although the group of students in the study were highly effective, high-achieving learners, they were not used to studying in a blended environment and many had not yet developed appropriate strategies or modified existing ones to be effective to the context. We should therefore not expect students to be equally effective in a new mode of learning and some may benefit from more directed support for scaffolding and developing SRL skills.

This study also note that the preferred ways of study and effective practice reported by students are many and varied and, with greater opportunities for how, what and when they study, even students on "traditional" university courses may now be studying in many different ways. Although it is likely that current generic dimensions such as time management are just as important as before, it may be that they are evidenced in different, unexpected ways for different students. There may also be additional dimensions which should be considered.

Although this study present findings from a small data sample it points to a number of areas for future implementation and exploration. Firstly, in line with the action research approach, students' SRL could in the future be tested early in the course with the MOOC component being ideally placed to provide personalised support for each student in aspects which they may benefit from developing further. Secondly, for students in the cohort studied in this paper, a longitudinal study will track how their SRL develops as they progress through the degree. We feel it is important to gain further qualitative data to understand how students work in practice and the strategies they adopt when confronted with different modes of learning. Finally, it is necessary to consider the conceptualisation of SRL to understand if existing instruments could be adapted to provide more accurate assessment of the effectiveness of learners' self-regulation.

\author{
Abbreviations \\ SRL - Self-regulated Learning \\ MOOCs - Massive Open Online Courses \\ GS - Goal Setting \\ TS - Task Strategies \\ TM - Time Management \\ ES - Environment Structuring \\ HS - Help Seeking \\ SE - Self-Evaluation \\ SPSS - Statistical Package for the Social Sciences \\ OSLQ - Online Self-Regulated Learning Questionnaire \\ MOSLQ - MOOC Online Self-Regulated Learning Questionnaire
}




\section{References}

Bandura, A. (1991). Social cognitive theory of self-regulation. Organisational behaviour and human decision processes, 50(2), $248-287$.

Bandura, A. (1997). Self-efficacy: The exercise of control, Freeman, New York, NY.

Barnard, L., Paton, V., \& Lan, W. (2008). Online self-regulatory learning behaviors as a mediator in the relationship between online course perceptions with achievement. The International Review of Research in Open and Distributed Learning, 9(2), pp. 1-11.

Barnard, L., Lan, W. Y., To, Y. M., Paton, V. O., \& Lai, S. L. (2009). Measuring self-regulation in online and blended learning environments. The Internet and Higher Education, 12(1), 1-6.

Beetham, H., \& Sharpe, R. (2007). Rethinking pedagogy for a digital age: Designing and delivering elearning, Routledge, London and New York.

Beetham, H., \& Sharpe, R. (2013). Rethinking pedagogy for a digital age: Designing for 21st century learning (vol. 711), Routledge, New York, NY.

Bergmann, J., \& Sams, A. (2012). Flip Your Classroom: Reach Every Student in Every Class Every Day, ISTE, ASCD, Alexandria, VA.

Biggs, J. B. (2011). Teaching for Quality Learning at University: What the Student Does, McGraw-Hill Education, Philadelphia, PA.

Boekaerts, M., \& Corno, L. (2005). Self-regulation in the classroom: A perspective on assessment and intervention. Applied Psychology, 54, 267-99.

Bowen, V. S. (1996), "The relationship of locus of control and cognitive style to self-instructional strategies, sequencing, and outcomes in a learner-controlled multimedia environment", Dissertation Abstracts International Section A: Humanities \& Social Sciences, Vol. 56, No. 10-A, 3922.

Broad, M. (1999). The dynamics of quality assurance in online distance education. Electronic Journal of Instructional Science and Technology, 3(1), 12-21.

Bruff, D. O., Fisher, D. H., McEwen, K. E., \& Smith, B. E. (2013). Wrapping a MOOC: Student perceptions of an experiment in blended learning. Journal of Online Learning and Teaching, 9(2), 187.

Chang, M. M. (2007). Enhancing web-based language learning through self-monitoring. Journal of Computer Assisted Learning, 23(3), 187-196.

Cunningham, C. A., \& Billingsley, M. (2002). Curriculum webs: A Practical Guide to Weaving the Web into Teaching and Learning, Allyn and Bacon, Boston, MA.

Dweck, C., \& Grant, H. (2008). Self-theories, goals and meaning. In J. Shah, \& W. Gardner (Eds.), Handbook of Motivation Science. New York: The Guildford Press. 
Fournier, H., Kop, R., and Sitlia, H. (2011). "The value of learning analytics to networked learning on a personal learning environment", First International Conference on Learning Analytics and Knowledge 2011, Banff, Alberta, Canada, February 27-March 1, 2011.

Fulton, W.K., 2012, "Community learning: Broadening the base for collaborative action", National Civic Review, 101(3), pp.12-23.

Graham, C. R. (2006). Blended Learning Systems. CJ Bonk \& CR Graham, The Handbook of Blended Learning: Global Perspectives, Local Designs, Pfeiffer, San Francisco, CA.

Herreid, C. F., \& Schiller, N. A. (2013). Case studies and the flipped classroom. Journal of College Science Teaching, 42(5), 62-66.

Kramarski, B., \& Mizrachi, N. (2006). Online discussion and self-regulated learning: Effects of instructional methods on mathematical literacy. The Journal of Educational Research, 99(4), 218-231.

Lan, W. Y. (1996). The effects of self-monitoring on students' course performance, use of learning strategies, attitude, self-judgment ability, and knowledge representation. The Journal of Experimental Education, 64(2), 101-115.

Lan, W. Y., Bremer, R., Stevens, T., \& Mullen, G. (2004). Self-regulated learning in the online environment. In annual meeting American Educational Research Association, San Diego, California.

López-Pérez, M. V., Pérez-López, M. C., \& Rodríguez-Ariza, L. (2011). Blended learning in higher education: Students' perceptions and their relation to outcomes. Computers \& Education, 56(3), 818-826.

Lynch, R., \& Dembo, M. (2004). The relationship between self-regulation and online learning in a blended learning context. The International Review of Research in Open and Distributed Learning, 5(2), pp. 1-16.

Mayes, T. and De Freitas, S. (2007), in Beetham, H. and Sharpe, R. (Eds), 'Learning and E-learning the Role of Theory' in Rethinking Pedagogy in the Digital Age, Routledge, pp. $13-25$.

McManus, T. F. (2000). Individualizing instruction in a web-based hypermedia learning environment: Nonlinearity, advance organizers, and self-regulated learners. Journal of Interactive Learning Research, 11(2), 219.

Milligan, C., Littlejohn, A., \& Hood, N. (2016). Learning in MOOCs: A comparison study. Proceedings of the European Stakeholder Summit on experiences and best practices in and around MOOCs (EMOOCS 2016), 15.

Oliver, M. (2016, July). Of clouds and cables: what do students need when they learn with technology? In Proceedings of the The 11th International Knowledge Management in Organizations Conference on The changing face of Knowledge Management Impacting Society (p. 2). ACM.

Onah, D. F. O., \& Sinclair, J. E. (2015, November). Measuring self-regulated learning in a novel e-learning platform: eLDa. In Proceedings of the 15th Koli Calling Conference on Computing Education Research (pp. 167-168). ACM. 
Onah, D. F. O. and Sinclair, Jane (2016) An empirical investigation of students' perceptions of self-regulated learning in Online Blended Learning : a case study of a novel E-learning platform. In: 8th International Conference on Education and New Learning Technologies (EDULEARN16), Barcelona, Spain, 4-6 Jul 2016. Published in: EDULEARN16 Proceedings

Onah D.F.O., Sinclair J.E. (2017) A Multi-dimensional Investigation of Self-regulated Learning in a Blended Classroom Context: A Case Study on eLDa MOOC. In: Auer M., Guralnick D., Uhomoibhi J. (eds) Interactive Collaborative Learning. ICL 2016. Advances in Intelligent Systems and Computing, vol 545. Springer, Cham.

Orsini-Jones, M. (2015) Integrating a MOOC into the MA in English Language Teaching at Coventry University, Higher Education Academy (HEA) Innovative Pedagogies Series, Heslington, York, UK.

Pintrich, P. R. (1999). The role of motivation in promoting and sustaining self-regulated learning. International Journal of Educational Research, 31, 459-470.

Rovai, A. P., \& Jordan, H. (2004). Blended learning and sense of community: A comparative analysis with traditional and fully online graduate courses. The International Review of Research in Open and Distributed Learning, Vol. 5 No.2, pp.1-13.

Schunk, D.H. and Bursuck, W., (2012), "Self-regulation and disability", Handbook of positive psychology and disability, pp.265-278.

Sharma, P., \& Barrett, B. (2011). Blended learning: Using technology in and beyond the language classroom, Macmillan Education, Oxford.

Shea, P., \& Bidjerano, T. (2010). Learning presence: Towards a theory of self-efficacy, self-regulation, and the development of a communities of inquiry in online and blended learning environments. Computers \& Education, 55(4), 1721-1731.

Sun, Z., Xie, K., \& Anderman, L. H. (2018). The role of self-regulated learning in students' success in flipped undergraduate math courses. The Internet and Higher Education, 36, 41-53.

Tallent-Runnels, M. K., Thomas, J., Lan, W. Y., Cooper, S., Ahern, T. C., \& Xiaoming, L. (2006). New models of learning: A review of research on the use of technology in online courses. Review of Educational Research, 76(1), 93-135.

Taylor, C., Deakin Crick, R., Huang, S., Davies, R., \& Carhart, N. (2017). Learning Frameworks for Future Infrastructure Provision. Paper presented at International Symposia on Next Generation Infrastructure , London, United Kingdom.

Ting, K. Y., \& Chao, M. S. (2013). The application of self-regulated strategies to blended learning. English Language Teaching, 6(7), p26.

Winters, F. I., \& Azevedo, R. (2005). High-school students' regulation of learning during computer-based science inquiry. Journal of Educational Computing Research, 33(2), 189-217.

Zimmerman, B. J. (1998), “Academic studying and the development of personal skill: A self-regulatory perspective”, Educational Psychologist, Vol.33 Nos 2-3, pp. 73-86. 
Zimmerman, B. (2000). Attaining self-regulation. A social cognitive perspective. In M. Boekaerts, P. R. Pintrich, \& M. Zeidner (Eds.), Handbook of self-regulation (pp. 13-39). San Diego, CA: Academic Press.

Zimmerman, B. J. (2008). Investigating self-regulation and motivation: Historical background, methodological developments, and future prospects. American Educational Research Journal, 45(1), 166183.

Zimmerman, B. J., Bonner, S., \& Kovach, R. (1996). Developing self-regulated learners: Beyond achievement to self-efficacy. American Psychological Association, Washington, DC. 


\section{Declarations}

Availability of data and materials: There are no data available for submission

Competing Interest: None

Funding: None

\section{Author's contributions:}

The corresponding author conducted the research and developed the eLDa platform tool that was used to collect the data in this study. The second author assist in conducting the focus group discussion and help in organising the sections. The third author contributed in writing the result analysis section and help in interpreting part of the findings. All authors in this paper contributed in writing and revising the entire paper.

\section{Acknowledgment:}

The first author wishes to acknowledge Mr. Adakole S. Onah's financial support in his research, family members and friends for their moral support.

\section{About the authors}

Dr Daniel Onah is a Lecturer in the Department of Information Studies at University College London. He received his $\mathrm{PhD}$ in Computer Science from the University of Warwick and MSc (Eng.) degree in Computer Systems Engineering (software systems) from the University of East London, UK. He is a fellow of the UK Higher Education Academy. His current research focuses on artificial intelligence, machine learning, natural language processing, educational technology and the design of interactive e-learning and software systems. Daniel F.O. Onah is the corresponding author and can be contacted at: d.onah@ucl.ac.uk

Dr Elaine Pang is an Educational Developer in Educational Development, Department of People and Organisational Effectiveness at Lancaster University. She was formerly an Assistant Professor in the School of Education at the University Nottingham (Malaysia campus). She received her $\mathrm{PhD}$ in Education from the University of Warwick, UK in 2018. She is a Fellow (FHEA) of the Higher Education Academy, UK.

Dr Jane Sinclair is a Professor in the Department of Computer Science at the University of Warwick, UK. She received the $\mathrm{PhD}$ degree in Computer Science from the Open University, UK in 1997. Her research interests in the area of educational technology are currently focused on MOOC pedagogy, learner engagement and the use of virtual learning environment. 